\title{
ESPAÇOS URBANOS INCLUSIVOS: A UTILIZAÇÃO DA ÁUDIO-DESCRIÇÃO E DA SINALIZAÇÃO TÁTIL PARA INCLUIR PESSOAS COM DEFICIÊNCIA VISUAL
}

\section{INCLUSIVE URBAN SPACES: THE USE OF THE AUDIO DESCRIPTION AND GUIDE FLOORS TO INCLUDE VISUALLY IMPAIRED PEOPLE}

\section{SILVEIRA, CAROLINA STOLF}

Mestre em Arquitetura e Urbanismo, doutoranda do Programa de Pós Graduação em Arquitetura e Urbanismo da Universidade Federal de Santa Catarina - POSARQ UFSC. carolinastolf@gmail.com

\section{DISCHINGER, MARTA}

Ph.D., orientadora e professora associada do Programa de Pós Graduação em Arquitetura e Urbanismo da Universidade Federal de Santa Catarina - POSARQ UFSC. martadischinger@gmail.com

\section{RESUMO}

Os espaços públicos urbanos, por vezes, apresentam diversas barreiras na locomoção e uso pleno, sendo as pessoas com deficiência as mais afetadas. Pessoas com cegueira ou baixa visão são privadas de usufruir de determinados espaços quando esses são projetados desconsiderando aqueles que não podem enxergar. 0 direito das pessoas com deficiência à ambientes acessíveis e em igualdade de oportunidades é assegurado por lei, entretanto, arquitetos e planejadores urbanos apresentam dificuldades em projetar espaços para todos. A busca por cidades multi-sensoriais é um desafio almejado e faz parte do tema deste artigo, o qual apresenta duas aplicações na cidade de Joinville, Santa Catarina, Brasil: a áudio-descrição em mirante, um espaço turístico e de lazer da cidade e a aplicação dos pisos táteis em estação de ônibus. Esses exemplos apresentam algumas das formas de como oferecer espaços inclusivos e que promovam a independência de seus usuários. PALAVRAS-CHAVE: espaço público; pessoa com deficiência visual; áudio-descrição; pisos táteis.

\section{ABSTRACT}

Sometimes, public spaces, presents several types of barriers for locomotion and usability. People with disabilities are the most affected. People with blindness or low vision are deprived of enjoying certain places when they are projected disregarding those who cannot see. The right of people with disabilities to accessible and equal opportunities environments it is guaranteed by law, however, architects and urban planners have difficulties in designing spaces for all. The search for multi-sensory cities is a desired challenge and is part of the theme of this article, which presents two applications in the city of Joinville, Santa Catarina, Brazil: the audio description about a tourist and leisure urban space, and the tactile floors in a bus station. These examples show how began inclusive spaces and promote independence of the users.

KEYWORDS: public space; visually impaired people; audio description; tactile floors. 


\section{INTRODUÇÃO}

Dentre os princípios da Convenção sobre os Direitos das Pessoas com Deficiência (BRASIL, 2014) está o de Igualdade de Oportunidades. Esse princípio define que o sistema geral da sociedade - meio físico e cultural, moradia e transporte, serviço social e de saúde, oportunidades de educação e de trabalho, vida cultural e social inclusive instalações desportivas e de lazer - deve ser acessível a todos.

A Lei Brasileira de Inclusão (BRASIL, 2015) ou o chamado Estatuto da Pessoa com deficiência, assegura e promove condições de igualdade, exercício dos direitos e liberdades fundamentais, visando a inclusão social e a cidadania da pessoa com deficiência. Dentre outros, apresenta as diretrizes do desenho universal e a promoção de espaços acessíveis para todos, independente das condições físicas ou sensoriais do indivíduo, que devem ser atendidas por arquitetos, urbanistas, engenheiros, designers e demais profissionais envolvidos como $o$ ato de projetar e executar espaços, mobiliários, objetos, serviços e equipamentos para a utilização das pessoas.

Um dos desafios das cidades na atualidade é garantir e efetivar o princípio de igualdade de oportunidades nos diversos espaços públicos urbanos. Muitas vezes, faltam corpo técnico, recursos financeiros e/ou vontade política para colocá-lo em prática através do desenho universal ${ }^{1}$ e recursos de acessibilidade disponíveis.

Herssens (2011) expõe que uma cidade multi-sensorial é aquela que proporciona espaços para que o maior número possível de pessoas possa usufruir, ou seja, projetar espaços acessíveis para mais pessoas e suas diferentes habilidades físico-sensoriais, de forma a proporcionar experiências que não sejam estritamente visuais, utilizando-se os demais canais sensoriais do ser para tornar os espaços inclusivos.

Em virtude do doutorado da autora (Silveira, orientada por Dischinger), desde 2015, desenvolve-se pesquisa com pessoas com cegueira e baixa visão no uso dos espaços e do transporte público urbano, envolvendo mais de 200 pessoas residentes em diversas regiões do Brasil. A coleta de informações ocorre através de questionários, entrevistas, passeios acompanhados e grupo focal digital, abordando os temas de orientação e mobilidade no transporte público urbano, utilização da áudio-descrição, pisos e mapas táteis, dentre outros. A abordagem metodológica é qualitativa e descritiva, pois envolve comportamentos e opiniões de pessoas com cegueira e baixa visão, relacionando as variáveis e documentando relatos.

Mediante a função de trabalho desempenhada pela autora durante certo período na Fundação Instituto de Pesquisa e Planejamento para o Desenvolvimento Sustentável de Joinville/SC (Fundação IPPUJ), foi possível desenvolver dois projetos específicos que corroboraram e foram embasados a partir dos estudos da pesquisa de doutorado, os quais são descritos neste artigo: a áudio-descrição do Mirante de Joinville e o sistema de informação tátil de uma estação de ônibus da cidade.

\section{A PESSOA COM DEFICIÊNCIA VISUAL}

A cegueira é um atributo, uma condição que você se encontra, não se denomine cego. [...] você é um ser humano e tem uma identidade. [...] Me lembro de uma situação [...] ela me perguntou 'você prefere ser chamado de deficiente visual ou cego?' e eu respondi 'me chame de J.C. que está muito bem, esse é meu nome, essa é minha identidade. A minha condição não pode me designar. (Informante da pesquisa de doutorado, com cegueira, de Florianópolis/SC) ${ }^{2}$

De acordo com a Classificação Internacional de Doenças (OMS, 2006), a função visual é dividida em quatro níveis: visão normal; deficiência visual moderada; deficiência visual grave; e cegueira.

A deficiência visual moderada e grave são comumente agrupadas sob o termo "baixa visão". Baixa visão é a perda severa da visão com vários graus de visão residual. A capacidade funcional da visão é reduzida decorrente de inúmeros fatores isolados ou associados, tais como baixa acuidade visual, redução importante do campo visual, alterações corticais e/ou de sensibilidade aos contrastes, que interferem ou que limitam o desempenho visual do indivíduo.

[...] varia de pessoa para pessoa, essa questão de nós dizermos assim, 10\% de visão, para uma pessoa, pode ser apenas ela perceber vultos. Tem pessoas que a perda visual é só central, no foco da visão e tem pessoas que é apenas na visão periférica, dos lados. A minha perda visual é no foco, no centro da visão e eu só consigo contar quantos dedos tem na minha mão à $15,20 \mathrm{~cm}$ de distância do meu rosto. Eu consigo perceber obstáculos só com a bengala. Eu consigo perceber contrastes, do cabelo, pele da pessoa, só muito próximo de mim.

Informante com baixa visão, de Rio Branco/AC. (2)

A cegueira total pressupõe completa perda de visão. A visão é nula, isto é, nem a percepção luminosa está presente. Com cegueira parcial, o indivíduo é capaz de identificar a direção de onde provém luz (distinguir claridade e escuridão). 
A cegueira pode ser congênita ou adquirida, segundo Amiralian (1997) é considerada cegueira adquirida a perda da visão a partir dos cinco anos. Os casos de cegueira anterior a essa idade são chamados de cegueira congênita. A delimitação da idade de cinco anos para o diagnóstico de cegueira adquirida é fruto de pesquisas que não identificaram memória visual em pessoas com cegueira que perderam a visão antes dessa idade.

As causas mais frequentes para a cegueira ou baixa visão congênitas são: Retinopatia da Prematuridade (por imaturidade da retina em virtude de parto prematuro ou por excesso de oxigênio na incubadora); Corioretinite, por toxoplasmose na gestação; Catarata congênita (rubéola, infecções na gestação ou hereditária); Glaucoma congênito (hereditário ou por infecções); Atrofia óptica por problema de parto (hipoxia, anoxia ou infecções perinatais); Degenerações retinianas (diabetes, Síndrome de Leber, Retinose Pigmentar); e Deficiência visual cortical (encefalopatias, alterações de sistema nervoso central ou convulsões).

As causas mais frequentes para a cegueira ou baixa visão adquiridas são: Diabetes (doença crônica provocada pelo mau funcionamento do pâncreas); Descolamento de Retina; Glaucoma; Catarata; Degeneração Senil; e Traumas Oculares.

A Associação Sueca de Deficientes Visuais exemplificou o nível de visão para diferentes tipos de deficiência visual em um mesmo ambiente:

Figura 1: Simulação da visão de um mesmo ambiente por diferentes deficiências visuais.

Diabetes Catarata Glaucoma

Retinose Pigmentar
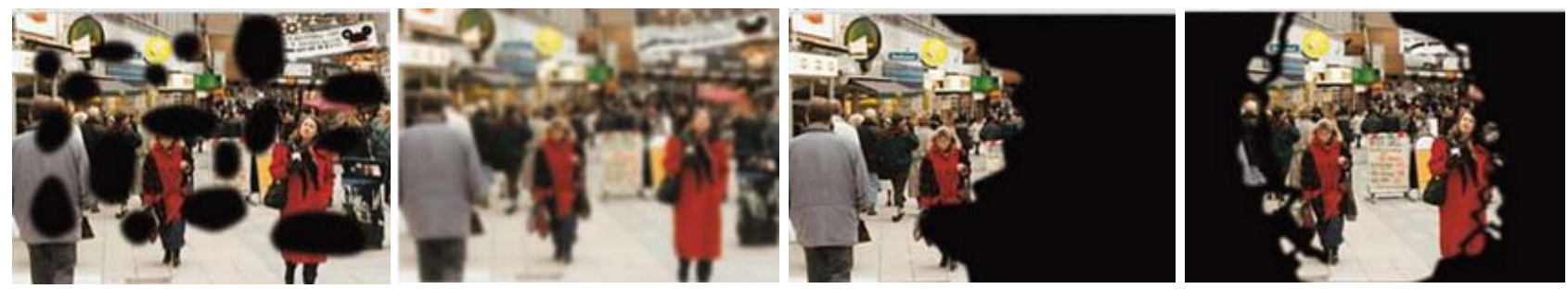

Fonte: Associação Sueca de Deficientes Visuais. 2016. Disponível em: http://www.srf.nu/om-synskador/de-vanligasteogonsjukdomarna/. Acessado em janeiro de 2016. Descrição das imagens: Pessoa com diabetes é representada na foto vendo várias manchas pretas. Pessoa com catarata, vendo toda a cena embaçada. Pessoa com Glaucoma com macha preta da metade da imagem para a direita. Pessoa com Retinose Pigmentar com visão tubular.

A Organização Mundial de Saúde (OMS, 2014) definiu em 1977, com base em conhecimentos médicos, que uma pessoa é considerada legalmente cega quando apresentar acuidade visual de 0 a 20/200 (enxergam a 20 pés ou $6,10 \mathrm{~m}$ de distância aquilo que uma pessoa com visão normal enxerga a 200 pés ou $60,96 \mathrm{~m}$ - 1 pé equivale à $0,3048 \mathrm{~m}$ ), no melhor olho após correção com ajuda de óculos, ou que tenham no máximo um ângulo visual de $10^{\circ}$ de amplitude (uma pessoa de visão normal tem $180^{\circ}$ ). Já uma pessoa com baixa visão é àquela que possui acuidade visual de $20 / 200$ pés a $20 / 70$ pés no melhor olho, após correção máxima, com campo visual correspondente ou menor que $20^{\circ}$, ou seja, enxergam a $6,10 \mathrm{~m}$ de distância aquilo que uma pessoa com visão normal enxerga a $60,96 m$ (200 pés) ou a $21,33 m$ (70 pés). Sendo assim, considera-se pessoa com deficiência visual aquela que possui baixa visão ou cegueira.

Segundo a Organização Mundial da Saúde (OMS, 2014), em 2010 foram contabilizados no mundo cerca de 285 milhões de pessoas com deficiência visual, das quais cerca de 39 milhões são cegas e 246 milhões têm baixa visão. Cerca de $90 \%$ das pessoas com deficiência visual vivem em países em desenvolvimento e $82 \%$ das pessoas com cegueira têm 50 anos ou mais.

Segundo dados do Censo de 2010 do Instituto Brasileiro de Geografia e Estatística (IBGE, 2010), dentre os 190.755.799 de habitantes no Brasil, 35.774.392 de pessoas declararam ter deficiência visual (incapacidade visual, mesmo com o uso de lentes), dessas, 29.211.482 afirmaram que tinham alguma dificuldade de enxergar, 6056533 disseram ter grande dificuldade (baixa visão) e 506.377 informaram que não conseguem enxergar de modo algum (cegueira).

As pesquisas realizadas pela OMS em 2010 indicam que, se iniciativas de alcance mundial e regional não forem tomadas, em 2020 existirão no mundo 75 milhões de pessoas cegas e mais de 225 milhões de pessoas com baixa visão. No Brasil, os cálculos apontam para a existência de 1,1 milhões de cegos $(0,6 \%$ da população estimada) e cerca de 4 milhões de pessoas com deficiência visual séria em 2020. Consideram que entre $60 \%$ e $75 \%$ dos casos de cegueira e baixa visão podem ser evitáveis e/ou curáveis.

De forma a previnir e tratar erros de refração e patologias oculares, Schneider (2012) sistematizou uma série de exercícios terapêuticos para os olhos, baseado no método de Willian Bates (1860 - 1931), médico e oftalmologista americano. Intitulado "Self-Healing" ou "Yoga for eyes", o método de Schneider apresenta-se como uma ferramenta complementar de prevenção e tratamento, principalmente nos casos em que a 
medicina cartesiana atinge suas limitações. Além disso, Schneider afirma, por experiência própria e por centenas de casos de pessoas que aplicaram o método, que problemas visuais podem ser evitados, tratados, reduzidos e até mesmo solucionados. Como outras formas de tratamento alternativos para problemas visuais pode-se citar a medicina oriental, com o uso da acupuntura, eletro e micro acupuntura, eletroestimulação e ervas medicinais.

\section{Os sentidos além da visão}

[...] quando se perde um dos sentidos, no nosso caso, a visão, existem os 4 sentidos remanescentes, e não existe compensação orgânica dos demais sentidos como muitos pensam, que a pessoa cega desenvolve mais a audição, mas sim, sentidos que nós vamos usar para diferentes situações. [...] Eu uso todos meus sentidos para me locomover, não consigo colocar em ordem hierárquica o som, e depois quem sabe o tato, depois o olfato ou o paladar, isso tudo é usado simultaneamente [...] em cada situação tu vai observar que precisa mais de um ou de outro [...] e muitos dos sentidos você usa sem perceber. Assim como a visão [...] as pessoas comem pelos olhos, ouvem pelos olhos, sentem cheiro pelos olhos e tateiam pelos olhos. [...] pela imagem você sente pelos outros sentidos, pela memória, pela experiência. E assim acontece com os outros sentidos [...] memória olfativa [...] memória tátil. [...] não vejo como determinar um sentido mais importante que o outro (Informante com cegueira, de Florianópolis/SC) ${ }^{2}$

Os sentidos remanescentes de pessoas cegas envolvem as percepções não visuais, através da audição (sistema auditivo), o tato (sistema háptico, principalmente o tato ativo), o olfato (sistema olfato-paladar), a cinestesia, a memória muscular e o sentido vestibular, compondo o sistema básico de orientação da teoria desenvolvida James Gibson (GIBSON, 1966), psicologista americano, Ph.D. no campo da percepção. Para pessoas com baixa visão o aproveitamento máximo de qualquer grau de visão é utilizado para sua orientação e mobilidade.

Os ouvidos constituem-se como o principal órgão sensorial à longa distância, é o único meio pelo qual a pessoa com cegueira pode perceber a distância e a profundidade dos ambientes. Possibilita estabelecer as relações espaciais, conforme descrito por informante da pesquisa, com cegueira, de Florianópolis, o qual relata que percebe a configuração espacial pela mudança da reverberação do som: "quando o som retorna rapidamente, significa que as paredes estão próximas e o ambiente é pequeno; quando o som demora a retornar ou causa eco, as paredes estão distantes e o ambiente é amplo". Além disso, é possível saber a natureza e a localização da fonte sonora.

Através do tato, pessoas com cegueira podem obter muitas informações para sua orientação. A bengala longa torna-se extensão das mãos. Os pés percebem diferentes texturas e desníveis no piso, podendo detectar pisos táteis e reconhecer uma travessia de pedestres, por exemplo, como demonstrado em Passeio Acompanhado (3) com informante com cegueira de Joinville/SC, em que reconheceu a travessia da rua pela guia rebaixada e mudança no tipo e nível do piso. Outro exemplo, ocorreu com a informante com cegueira, de São Paulo/SP, que utilizou pista tátil para deslocar-se pela estação de metrô Vila Madalena:

Figura 2: Exemplos de orientação e mobilidade através do tato.
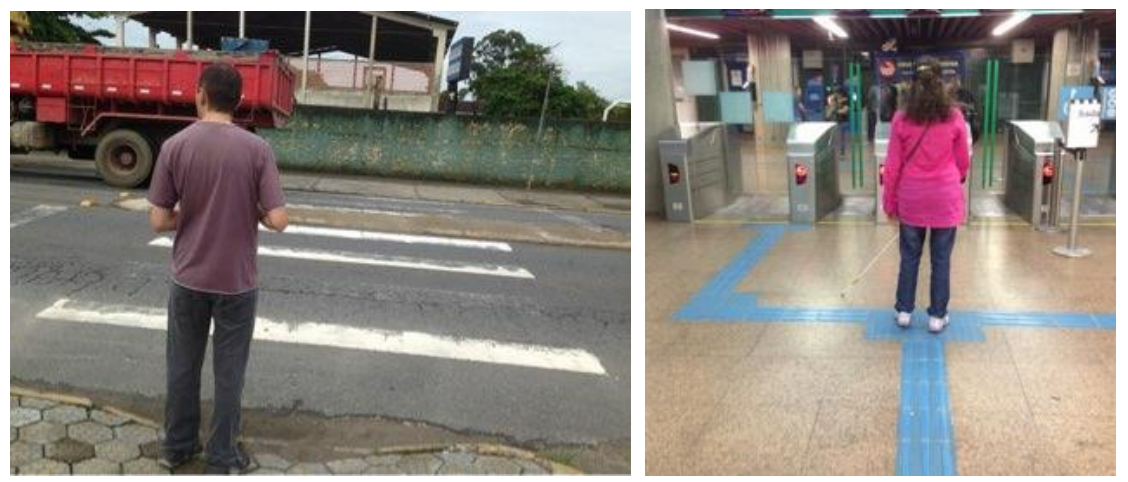

Fonte: Acervo Próprio. Descrição das imagens: à esquerda, o informante aguarda para atravessar posicionado ao fim da calçada em frente e ao centro da faixa de travessia de pedestres em Joinville/SC; à direita a informante está sobre pisos táteis alerta em um cruzamento de pista tátil, com opções de caminhada à esquerda e à direita, em estação de metrô de São Paulo, a sua frente, as catracas de acesso à estação. Ambas fotos estão com os informantes de costas.

Através do olfato, é possível identificar pontos comerciais, como farmácias, padarias, postos de combustível, loja de sapatos e zonas industriais, por meio de odores característicos desses locais. Assim, esses odores podem constituir-se como referenciais urbanos para a orientação e mobilidade, pois confirmam a posição do indivíduo durante seu deslocamento ao longo de uma rota.

Cinestesia é a sensibilidade para perceber os movimentos musculares ou das articulações, essa percepção nos torna conscientes da posição e do movimento de cada parte do corpo (BRASIL, 2003). 
A memória muscular é a repetição de movimentos em uma sequência fixa, que se convertem em movimentos automáticos. Muito comum em ambientes familiares internos e aqueles habitualmente utilizados, como em escadas, sem necessidade de contar os degraus. Outros exemplos que podem ser citados são: ao digitar uma senha, os músculos dos dedos memorizam os movimentos sem que saibamos, conscientemente, os dígitos; a coreografia de uma dança; os movimentos das mãos e pés ao tocar um instrumento musical; ou ainda, o que nos transmite a sensação de que já deveríamos ter chegado, por exemplo, a uma esquina conhecida ao longo de uma caminhada.

Além dos músculos, os processos de memorização, muitas vezes não conscientes, utilizam outras fontes, como memórias visual, verbal, cognitiva e auditiva - entendidos como menos expressivos na orientação e mobilidade de pessoas com deficiência visual que a memória muscular.

O sentido vestibular provê informações sobre a posição vertical do corpo e dos componentes rotatórios e lineares dos movimentos sobre o eixo de uma volta em graus (BRASIL, 2003). Virar a direita ou a esquerda ou seguir em frente, depende do senso de equilíbrio corporal, como virar em 90 graus ou em 45 graus em uma esquina.

Esse sentido alia-se constantemente aos demais, como por exemplo, quando se utiliza algum referencial, como piso tátil - exemplo de informante em São Paulo (Figura 3a), ou arbustos - exemplo de informante em Joinville (Figura $3 b$ ). O deslocamento é facilitado pelo tato dos pés e/ou bengala, mas sem referenciais podotáteis, a pessoa com deficiência visual utiliza principalmente a audição e o tato da pele com o movimento do ar, observado no deslocamento do informante de Florianópolis (Figura 3c) ${ }^{3}$.

Figura 3: Sentido vestibular aliado a demais sentidos para promover a orientação e o deslocamento.

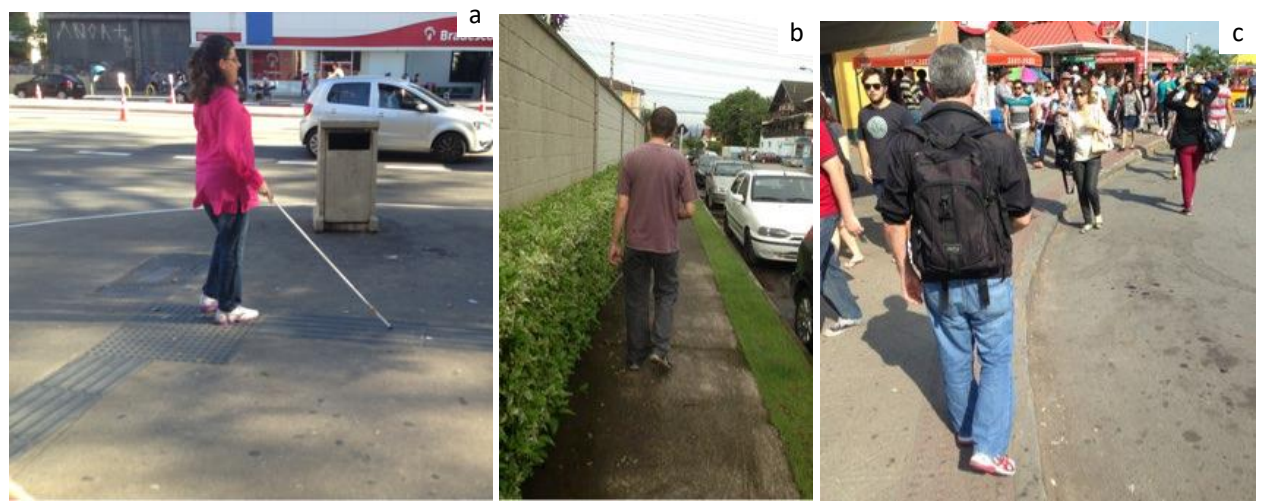

Fonte: Acervo Próprio. Descrição das Imagens: (a) informante de São Paulo caminha sobre piso tátil preto em esquina de calçada em concreto da Avenida Paulista. (b) informante de Joinville caminha em calçada estreita com arbusto do lado esquerdo e grama do lado direito; (c) informante de Florianópolis caminha em calçada, buscando balizar-se pelo meio fio e piso tátil alerta. Existem muitos pedestres na calçada e alguns na faixa de rolamento de veículos.

É possível concluir que todos os sentidos remanescentes são utilizados por pessoas com deficiência visual para sua orientação e mobilidade, uns mais que outros em determinadas situações. A capacidade de interagir com o ambiente e identificar características, não significa que a pessoa possui capacidades incomuns, como na audição ou tato, por exemplo, mas significa que, na ausência da visão, os demais sentidos ganham o foco perceptivo, tendo em vista que cerca de $85-90 \%$ dos estímulos de pessoas que enxergam são baseados em percepções visuais.

\section{OS RECURSOS DE ACESSIBILIDADE PARA AS PESSOAS COM DEFICIÊNCIA VISUAL}

Além das técnicas de orientação e mobilidade, geralmente ensinadas nas instituições de apoio às pessoas com deficiência visual para que possam aprender a orientar-se e deslocar-se de forma segura, eficiente e independente, tais como as técnicas do guia vidente, da auto-proteção, da bengala e do cão guia, existem diversos recursos de acessibilidade para pessoas com deficiência visual, tais como braille, leitores de tela, mapas e maquetes táteis. Destaca-se neste artigo a áudio-descrição e os pisos táteis para a inclusão de pessoas com cegueira ou baixa visão em espaços públicos urbanos.

A áudio-descrição consiste na descrição clara e objetiva de todas as informações que compreendemos visualmente. Na definição de Livia Motta, doutora em linguística e áudio-descritora brasileira: "é uma atividade de mediação linguística, uma modalidade de tradução intersemiótica, que transforma o visual em verbal [...]. Além das pessoas com deficiência visual, a áudio-descrição amplia também o entendimento de pessoas com deficiência intelectual, idosos e disléxicos"4. 
A primeira vez que a áudio-descrição apareceu formalmente descrita, foi na tese apresentada na Universidade de São Francisco pelo norte-americano Gregory Frazier, em 1975. Uma série de estudos começaram a ser feitos e os resultados favoráveis que foram sendo comprovados nessas primeiras experiências fizeram com que a técnica se desenvolvesse em teatros, museus e cinemas na década de 80 , como por exemplo em alguns filmes do Festival de Cannes em 1989 e na televisão no Reino Unido. Rapidamente a técnica estendeuse por alguns países da Europa. No Brasil, o primeiro filme a receber o recurso foi apenas em 2005.

Os pisos táteis, criados no Japão, são caracterizados pela diferenciação de textura em relação ao piso adjacente, no Brasil, constitui-se em duas tipologias: alerta ou linha guia. A cor do piso adjacente ao da sinalização tátil deve promover contraste, de forma a fornecer uma linha guia visual aos pedestres com baixa visão. A sinalização tátil direcional deve ser instalada no sentido do deslocamento das pessoas para indicar caminhos preferenciais e seguros de circulação, enquanto que a sinalização tátil alerta pode indicar, segundo a Associação Brasileira de Normas Técnicas (ABNT), Norma Brasileira (NBR) 9050 de 2015: a existência de desníveis, tais como o início e o término de degraus, escadas e rampas, bem como a existência de patamares; situações de risco permanente, como objetos suspensos não detectáveis pela bengala longa; mudanças de direção ou opções de percursos; travessias de pedestres; o posicionamento adequado do pedestre para 0 uso de equipamentos, como elevadores, equipamentos de auto-atendimento ou serviços.

De forma a especificar e detalhar a utilização da sinalização tátil no piso, foi desenvolvida a NBR 16.537 (ABNT, 2016), com diretrizes para a elaboração de projetos e instalação em degraus, rampas, escadas, elevadores, travessia de pedestres, limite de plataformas, elementos suspensos, balcões de atendimento, sinalização em calçadas, dentre outros. Apesar da norma não especificar como deve ser o layout de pista tátil em estações de transporte coletivo, a versão de 2004 da NBR 9050 especificou os locais de embarque em pontos de ônibus.

A seguir, apresentam-se as aplicações da áudio-descrição e dos pisos táteis em espaços públicos urbanos de Joinville-SC. No primeiro caso, o mirante da cidade, no segundo a estação de ônibus Sul, próxima à associação de pessoas com deficiência visual da cidade.

\section{4 ÁUDIO-DESCRIÇÃO DO MIRANTE DE JOINVILLE/SANTA CATARINA}

O Mirante de Joinville foi reinaugurado no dia 9 de março de 2016 e constitui-se em um espaço público com duas estruturas de mirante, um maior e outro menor (chamado de Janela) que se integram por uma trilha. Localiza-se no ponto mais alto do Morro da Boa Vista, região central da cidade, sendo possível visualizar a Baía Babitonga e boa parte da zona urbana, além de percorrer uma trilha em meio a Mata Atlântica. O acesso pode ser feito a pé, de bicicleta e por linhas exclusivas de ônibus. Foi projetado para ser um ponto turístico, mas tornou-se um ponto de lazer, recebendo Joinvilenses diariamente, que utilizam o caminho até o Mirante para esporte e lazer.

Incentivada pelas descobertas advindas da tese, a autora desenvolveu o projeto de áudio-descrição do Mirante e da Janela, sem custos financeiros, a partir dos depoimentos do autor do projeto, Vânio Lester Kuntze, arquiteto e urbanista, sobre a estrutura do Mirante e acerca da paisagem, com o geógrafo Jorge Luís Araújo de Campos. O projeto contou com o apoio da Associação Joinvilense para Integração dos Deficientes Visuais de Joinville (AJIDEVI) e da Radiodifusão de Informação da Fundação Cultural de Joinville, a qual realizou a gravação dos áudios na voz da radialista Tusi Helena de Sousa.

$\mathrm{Na}$ construção dos textos dos áudios, buscou-se descrever o que era visto, com informações relevantes sobre a arquitetura, a geografia e a configuração da área urbana. Percebeu-se que essas informações eram relevantes não apenas para quem não estava enxergando, mas também para visitantes da cidade ou moradores que não a conheciam tão bem. Assim, pensando-se nos turistas, o áudio foi traduzido para 0 alemão, inglês, francês e italiano.

A áudio-descrição mostrou-se promissora e cumpriu seu papel de inclusão das pessoas com deficiência visual no mirante da cidade, conforme alguns depoimentos a seguir, repercutindo intensamente na mídia local e estadual: "Dá para ter noção do que tem ao redor, na frente e ao lado e de onde está cada coisa" Jonas Oliveira, com cegueira, 29 anos. "Ali é a baía Babitonga, do outro lado o bairro Costa e Silva e ali o bairro Cubatão", José Alberto Miranda, baixa visão, 64 anos. - Depoimentos para a reportagem do Jornal Globo G1 Santa Catarina em 30 de abril de 20165. "Quando eu enxergava, vim aqui uma vez quando era criança. Hoje não enxergo, mas ouço. Legal conhecer a cidade que você mora, os pontos turísticos, para mim foi bem especial" Depoimento de Marilza Goes, com cegueira, para a reportagem do Jornal local "Notícias do Dia" do dia 30 de abril de $2016^{6}$ 
Figura 4: Pessoas com deficiência visual com a camiseta de homenagem ao aniversário de 35 anos da AJIDEVI, ouvindo a áudiodescrição no topo do Mirante de Joinville.

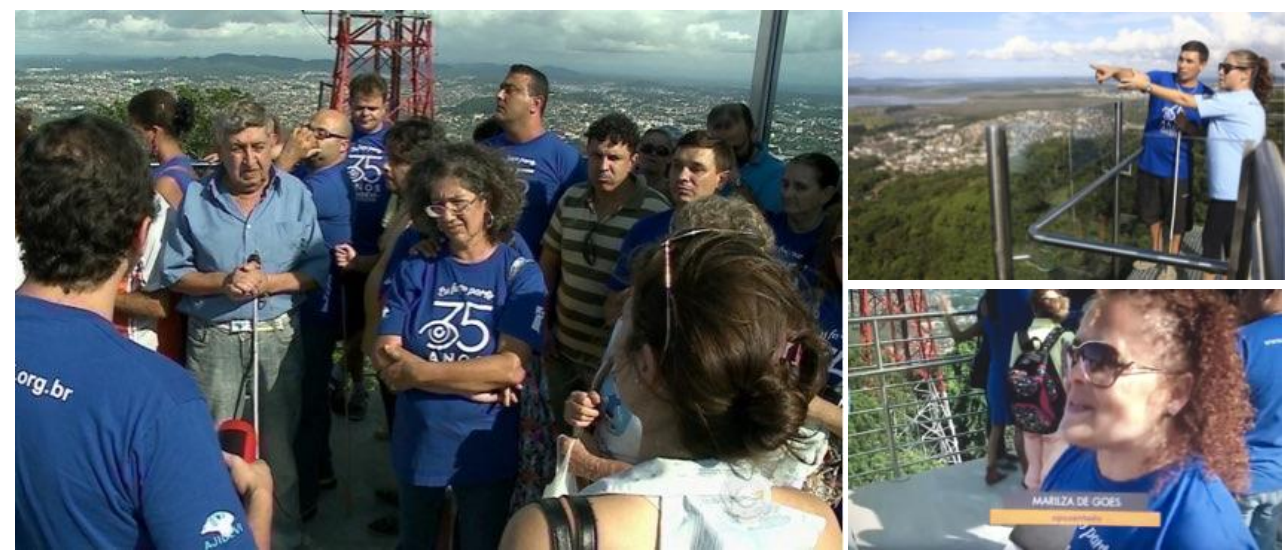

Fonte: Fotografias da reportagem do jornal G1 Santa Catarina em 30 de abril de 2016.

A seguir, a transcrição de trechos dos áudios ${ }^{7}$ :

Trecho do áudio sobre o Mirante:

"O Mirante é uma estrutura em concreto armado com acabamento aparente, tendo 14,5 metros de altura da plataforma de observação em relação ao solo. Além da plataforma, o Mirante é composto por escadarias, elevador, e, no nível do solo, existem sanitários e salas para informações turísticas, controle e segurança. A plataforma de observação possui dois balanços, um com vista para a Baía da Babitonga (ao Leste) com, aproximadamente, 7,5 metros, e outro (para o oeste) voltado para o centro da cidade com 5,5 metros. Todo o guarda-corpo do Mirante é de aço inox e no limite do balanço voltado para a baía, tem-se uma estrutura metálica com grade vazada no piso para que as pessoas possam observar a paisagem abaixo e terem a sensação de que estão em um espaço flutuante. Esse mirante é o ponto mais elevado do Morro da Boa Vista, onde a paisagem é marcada, em primeiro plano, pela área urbana e, em segundo plano, pela Baía da Babitonga. [...]"

Trecho do áudio sobre a Janela do Mirante:

"A Janela é um segundo mirante, mais baixo, de onde é possível visualizar a região oeste e noroeste da cidade, sem a interrupção visual das antenas e das torres de comunicação. $O$ acesso à Janela é realizado por passarela que passa sobre a rua de acesso ao mirante (R. Pastor Guilherme Rau), interligada à trilha ecológica elevada, que tem 600 metros de extensão, dentro da mata, no topo do morro. A trilha foi executada sobre estrutura de concreto, com deck em madeira, guarda-corpo de aço galvanizado a fogo e alguns ambientes de descanso durante o percurso. Próximo à Janela, tem-se lanchonete e sanitários de onde é possível visualizar parte da paisagem e as pessoas atravessando a passarela sobre a rua. A plataforma de observação da Janela tem altura, de aproximadamente, 15 metros e é composta por um balanço em estrutura metálica e deck de madeira, que avança cinco metros em relação à estrutura de apoio e sustentação da plataforma. Essa estrutura é constituída por dois grandes pilares, uma viga de travamento superior e outra de travamento inferior, abaixo do deck, configurando um pórtico de concreto aparente.[...]"

\section{SINALIZAÇÃO TÁTIL EM ESTAÇÃO DE ÔNIBUS DE JOINVILLE/SANTA CATARINA}

O sistema de informação tátil da Estação Sul da cidade era uma antiga solicitação da AJIDEVI, tendo em vista a proximidade da Estação com a Associação, frequentemente utilizada por seus usuários e também por visitantes com deficiência visual vindos de outras cidades.

O projeto de sinalização foi desenvolvido pela autora em 2016, através de consultas e acompanhamento do projeto pelos usuários com deficiência visual e professores de orientação e mobilidade da Associação, os quais ensinam seus alunos dentro e no entorno da estação.

A Estação localiza-se no sul da cidade de Joinville, com testada principal e acesso para os pedestres e ciclistas por avenida e acesso dos ônibus por rua lateral. Ao fundo, a estação é fechada por gradil. 
Após conversas e acompanhamento de pessoas com deficiência visual utilizando a Estação, observou-se que frequentemente não utilizavam o acesso de pedestres pela Avenida Santa Catarina e acessavam a Estação pelo acesso de veículos, devido a localização da Associação, o menor caminho e o mais seguro (por caracterizar-se por via local) ocorrer pela rua aos fundos. Considerando essas justificativas e a precariedade das calçadas da avenida, foi proposto um segundo acesso de pedestres ao fundo da Estação, facilitando o acesso das pessoas com deficiência visual e demais usuários do entorno.

Figura 5: À esquerda, acesso de veículos da Estação Sul, por onde frequentemente usuários com deficiência visual fazem o acesso. À direita, fundos da estação, fechada por gradil, rua por onde usuários circulam até o acesso de veículos - este local da imagem foi escolhido em projeto para o segundo acesso à Estação.
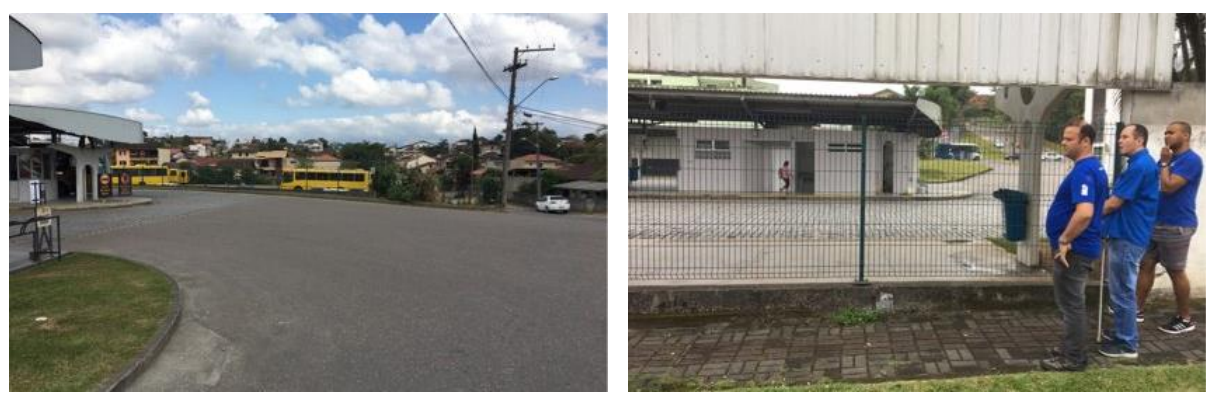

Fonte: Acervo próprio, em setembro de 2016.

É importante considerar que não apenas os usuários com deficiência visual eram expostos ao risco por acessar a Estação em um local de tráfego proibido para pedestres como também a questão de não serem contabilizados no sistema de transporte da cidade, o qual, através das catracas de acesso às estações da cidade e nos veículos, obtém um controle do número de usuários do sistema - importante estatística de monitoramento e planejamento do serviço.

Além dessas questões, o projeto considerou a necessidade de qualificar o deslocamento a pé e por bicicleta até a estação, com atenção às calçadas, travessias e vias para ciclistas no entorno da estação, conforme diretrizes estabelecidas no Plano Diretor de Transportes Ativos da cidade (PDTA Joinville, decretado em março de 2016), o qual a autora foi coordenadora e uma das autoras, devido sua atuação profissional.

O projeto seguiu as especificações da NBR 16.537/2016 e foram propostas placas de piso tátil emborrachado na cor preta (proporcionando alto contraste com o piso adjacente, de cor cinza claro, de agrado aos usuários envolvidos), dos tipos alerta (ao fim das plataformas e nas mudanças de direção) e direcional no caminho seguro a seguir e em cada um dos 18 pontos de embarque distribuídos pelas 4 plataformas da estação. $\mathrm{A}$ sinalização tátil no piso da estação fez conexão com o piso tátil proposto nas calçadas de acesso.

Figura 6: Visão geral do projeto de sinalização tátil na Estação Sul de Joinville. Retângulos em vermelho e azul localizando os recortes das próximas figuras, respectivamente.

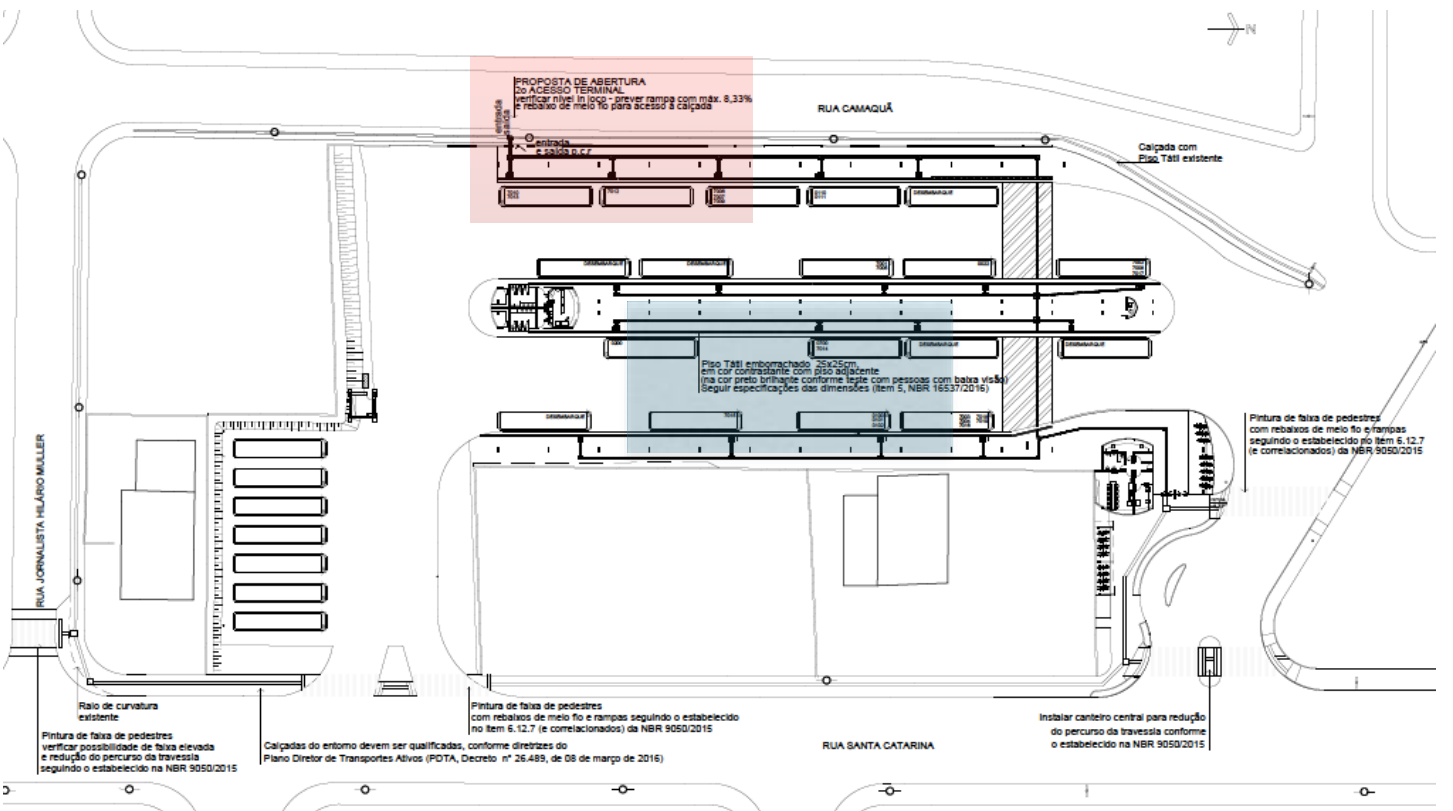

Fonte: Acervo Próprio. Setembro de 2016. 
Figura 7: Proposta de abertura de um segundo acesso de pedestres pela rua dos fundos da Estação Sul.

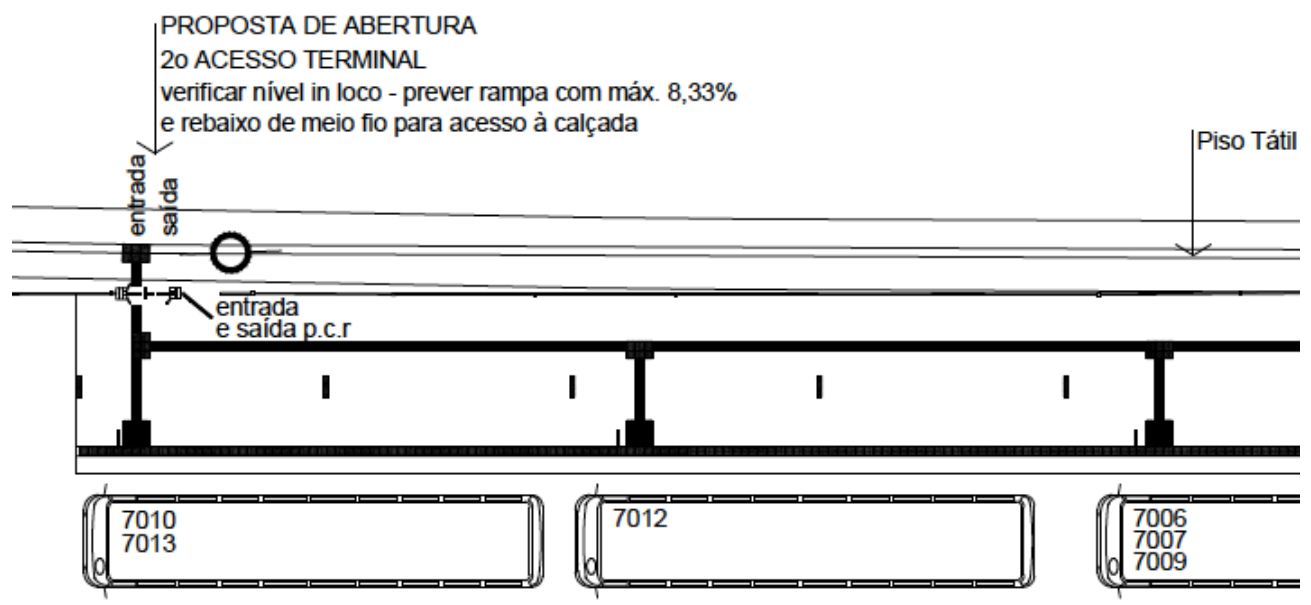

Fonte: Acervo Próprio. Setembro de 2016.

No intuito de proporcionar um sistema tátil mais eficiente, foram propostos totens com informações visuais e táteis (letras em relevo e em braille) em cada ponto de embarque, informando o número das linhas e frequência.

A localização da pista tátil no ponto de embarque foi definida conforme posicionamento dos veículos, o que na prática, os motoristas devem ser instruídos para tomarem o cuidado de estacionar o veículo posicionando a porta dianteira no alinhamento do piso tátil de embarque. Assim, as pessoas com cegueira não terão dificuldade em encontrar a porta de acesso do veículo, ganhando maior independência.

Figura 8: Recorte do projeto indicado os pontos de embarque nas plataformas e totem visual e tátil informativo com os números das linhas e frequência dos horários.

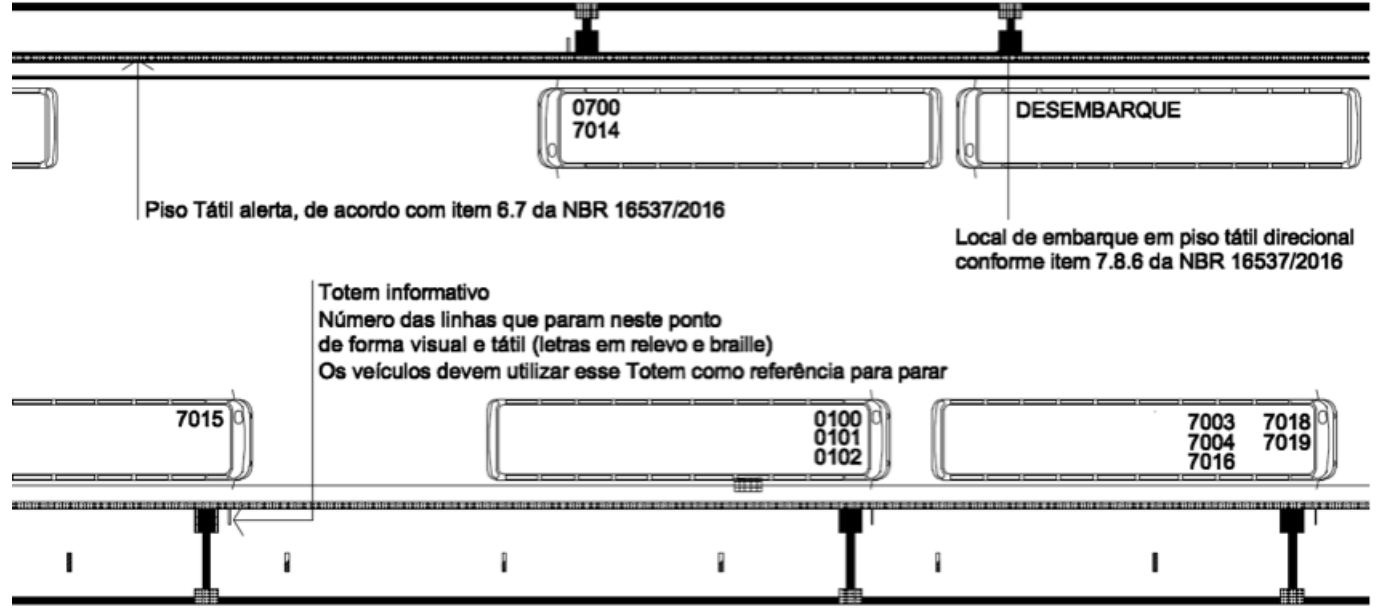

Fonte: Acervo Próprio, setembro de 2016.

Salienta-se que, em Joinville, as pessoas com deficiência visual costumam viajar nos bancos dianteiros do veículo por duas principais razões: 1) não haver sistema sonoro e dependerem do motorista para avisar quando devem desembarcar; e 2) não passarem pela catraca, pois o transporte é gratuito para pessoas com deficiência, assim, apenas validam o cartão no sistema de bilhetagem para serem contabilizados no sistema.

A instalação dos pisos táteis teve início em abril de 2017 através da administradora do serviço de transporte da cidade, com o acompanhamento dos usuários e funcionários da AJIDEVI. O intuito é repetir o projeto e aplicação nas outras 9 estações da cidade. Todavia, acredita-se que seja necessário realizar uma avaliação pós uso com usuários no intuito de aperfeiçoar o sistema e melhorá-lo perante possíveis problemas. A avaliação do material empregado também será testada com o tempo, verificando resistência e qualidade. Quanto aos totens, ainda não foi possível confeccioná-los, sendo necessário um trabalho de design gráfico e contratação do serviço. A seguir, algumas imagens do resultado da instalação dos pisos táteis. 
Figura 9: À esquerda, usuária com cegueira atravessa pista de rolamento de veículos sobre piso tátil direcional instalado na faixa de travessia de pedestres. Ao centro, usuário com cegueira, acompanhado de professores de orientação e mobilidade caminha sobre piso tátil direcional. À direita, usuária encontra setor de embarque por marcação específica no piso.

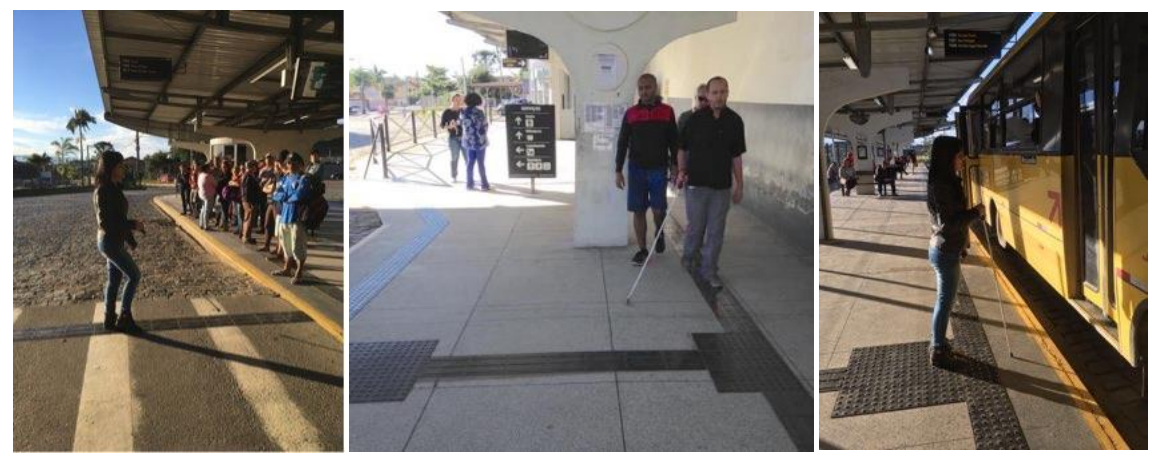

Fonte: Acervo fotográfico da AJIDEVI, 2017.

Como resultados, pode-se verificar a satisfação dos usuários com deficiência visual, a agilidade na caminhada e a facilidade em encontrar os setores de embarque. É importante dizer que alguns problemas já foram detectados, tais como: algumas placas que se soltaram nas travessias, devido ao movimento dos veículos; troca de aplicação do tipo das placas (nos setores de embarque aplicaram placas do tipo alerta e deviam ser, segundo projeto e norma, do tipo direcional; e alguns motoristas que não respeitam a marcação dos setores de embarque, devendo estacionar o veículo alinhando a porta frontal com a marcação tátil.

Apesar desses problemas identificados não impedirem o uso e a compreensão pelos usuários com cegueira e baixa visão, eles devem ser sanados e evitados nas próximas aplicações das demais 9 estações de ônibus da cidade. Os descolamentos das placas nas travessias de pedestres podem ser facilmente evitados com a aplicação de bisnaga de vedação ao redor de cada placa, enquanto que a atitude dos motoristas pode ser corrigida nos treinamentos realizados pelas empresas de transporte.

Além dos pisos táteis e totens informativos, espera-se que o sistema de transporte e estações da cidade tornem-se mais acessíveis e completos com a utilização da áudio-descrição e mapas táteis, considerando a complexidade de compreensão da malha urbana e seu sistema de transporte, principalmente por quem não pode enxergar.

\section{CONSIDERAÇÕES FINAIS}

Ações como a realizada no Mirante de Joinville, com o recurso de áudio-descrição, promovem a inclusão de pessoas com deficiência visual nos espaços em que não se supõe serem desfrutados por pessoas com cegueira. Essa ação, realizada sem custos financeiros, mostra-se promissora no Brasil, sabendo-se da dificuldade em implementar recursos considerados de alto custo para prefeituras.

Apesar das especificações das normas técnicas brasileiras acerca da sinalização tátil no piso, houve dúvidas no momento do projeto da estação de ônibus, considerando que as normas não apresentam esse elemento urbano, apenas a especificação pontual nos pontos de embarque para abrigos de ônibus e marcação ao fim de plataformas.

Embora existam pessoas com deficiência visual no Brasil que solicitem e prefiram a utilização dos pisos táteis direcionais como linha guia de balizamento, mesmo existindo paredes ou outro elemento guia na proximidade, conforme solicitação dos associados da AJIDEVI à prefeitura de Joinville, sabe-se que existe polêmica nacional a esse respeito, principalmente entre pessoas com baixa visão que dispensam o uso do piso tátil direcional - conforme pesquisa da autora a nível nacional através de questionário de 26 questões sobre o uso dos pisos táteis no Brasil em que 70 pessoas com deficiência visual, de diversas regiões responderam. Alguns respondentes fizeram menções como "eu quero poder andar por um caminho que eu escolho e não por um caminho que alguém escolheu por mim" ou "essas linhas levam a um preconceito de incapacidade e compara pessoas a veículos que andam sobre trilhos".

Observa-se que nos Estados Unidos e países europeus a utilização de pisos táteis direcionais é mais restrita, no sentido de utilizá-los como linhas guias para se caminhar sobre. Na realidade brasileira, por vezes a pista tátil direcional busca garantir um caminho seguro a seguir, considerando a falta de padronização e obstáculos constantes até e nos locais de acesso ao sistema do transporte coletivo.

No Brasil, o piso tátil alerta apresenta diversos significados, que por vezes, não são óbvios para pessoas com cegueira que estão utilizando o sistema tátil local pela primeira vez e sem informação prévia através de mapas 
ou descrições. A partir disso, tem-se conhecimento de pesquisas e desenvolvimento de uma terceira tipologia, apenas para indicar mudança de direção, diferenciando de situações de perigo potencial.

Pode-se concluir que as aplicações em Joinville foram recebidas com satisfação por usuários, que acima de tudo, mostraram-se envolvidos desde o projeto à execução. As iniciativas mostraram-se passíveis de serem realizadas através das prefeituras, institutos ou secretarias de planejamento urbano em parceria com radialistas e instituições de pessoas com deficiência visual, principalmente a áudio-descrição como aliada em projetos de arquitetura e urbanismo, podendo ser realizada com custos reduzidos ou até mesmo de forma gratuita, como ocorreu em Joinville.

Por fim, o envolvimento das pessoas com deficiência como informantes e participantes em projetos inclusivos é essencial para a efetividade e uso pleno pelos usuários foco.

\section{AGRADECIMENTOS}

A pesquisadora agradece a todos os participantes com deficiência visual da pesquisa de doutorado, especialmente aos associados representados pela AJIDEVI, a qual ativamente luta pelos direitos e inclusão da pessoa com cegueira e baixa visão em Joinville e região. Agradecimentos para a Fundação IPPUJ, à radialista Tusi Helena de Sousa, através da Fundação Cultural e à Passebus que se responsabilizou pela execução da aplicação dos pisos táteis da Estação Sul.

Agradecemos ainda à Coordenação de Aperfeiçoamento de Pessoal de Nível Superior - CAPES, a qual, através de bolsa de estudos durante parte da pesquisa para o desenvolvimento da tese de doutorado, permitiu a dedicação exclusiva da pesquisadora aos estudos.

\section{REFERÊNCIAS}

AMIRALIAN, M. L. T. M. (1997). Compreendendo o cego: uma visão psicanalítica da cegueira por meio de desenhosestórias. São Paulo: Casa do Psicólogo. 1997.

ASSOCIAÇÃO BRASILEIRA DE NORMAS TÉCNICAS. NBR 9050/2015. Acessibilidade a edificações, mobiliário, espaços e equipamentos urbanos. 2015.

elaboração de projetos e instalação. 2016

NBR 16.537/2016. Sinalização tátil no piso com diretrizes para a

BRASIL. Convenção sobre os Direitos das Pessoas com Deficiência. 5. ed. - Brasília. Secretaria de Direitos Humanos, Secretaria Nacional de Promoção dos Direitos da Pessoa com Deficiência, 2014.

. Lei Brasileira de Inclusão (Lei Federal 13.146/2015). Estatuto da Pessoa com deficiência, assegura e promove condições de igualdade, exercício dos direitos e liberdades fundamentais, visando a inclusão social e cidadania da pessoa com deficiência. Brasil. 2015.

Orientação e Mobilidade: Conhecimentos básicos para a inclusão da pessoa com deficiência visual. Ministério da Educação. Secretaria de Educação Especial. Brasília, 2003.

DISCHINGER, Marta. Designing for all senses: accessible spaces for visually impaired citizens. 260f. Thesis (for the degree of Doctor of Philosophy) - Department of Space and Process School of Architecture, Chalmers University of Technology. Göteborg, Sweden. 2000.

GIBSON, James J. The senses considered as perceptual systems. Boston: Houghton Mifflin. 1966.

HERSSENS, Jasmien. Designing Architecture for More. A Framework of Haptic Design Parameters with the Experience of People Born Blind. PHL University College-University Hasselt, K.U.Leuven, Flanders. Heverlee, België. 2011.

INSTITUTO BRASILEIRO DE GEOGRAFIA E ESTATÍSTICA (IBGE). População residente, por tipo de deficiência, segundo o sexo e os grupos de idade - Brasil. Censo demográfico 2010. Disponível em http://www.ibge.gov.br. Acessado em junho de 2015.

JOINVILLE. Plano Diretor de Transportes Ativos - PDTA. Decretado em 9 de março de 2016. Disponível em wwwold.joinville.sc.gov.br/public.

ORGANIZAÇÃO MUNDIAL DE SAÚDE (OMS). CID-10 Classificação Estatística Internacional de Doenças e Problemas Relacionados à Saúde. 10a rev. São Paulo. 2006.

Cegueira e deficiência visual. Ficha $\mathrm{n}^{\circ} 282$. Agosto 2014. Disponível em: http://www.who.int/features/factfiles/blindness/blindness_facts/es/index7.html. Acessado em fevereiro de 2015.

SCHNEIDER, Meir. Saúde Visual por toda a vida (Vision for Life). Editora Pensamento Cultrix. São Paulo/SP. 2012. 


\section{NOTAS}

${ }^{1}$ Conceito definido pelo arquiteto americano Ronald Mace em 1997, estabelecendo sete princípios: 1 . Uso equitativo; 2. Flexibilidade no uso; 3. Uso Simples e intuitivo; 4. Informação perceptível; 5. Tolerância ao erro; 6. Baixo esforço físico; 7. Dimensões apropriadas para o uso de todos;

2 Os relatos expostos neste artigo são transcrições das falas dos participantes com cegueira e baixa visão em grupo focal nacional criado em abril de 2015 reunindo 78 integrantes. A interação ocorre (grupo permanece ativo em 2017) de forma online através de aplicativo de mensagens de voz pelo telefone celular smartphone. Os temas discutidos foram orientados pela pesquisadora, relativos à pesquisa. Relatórios diários sobre as discussões feitas pelo grupo e as principais falas foram transcritas na íntegra, compondo a leitura dos temas investigados.

${ }^{3}$ Foram realizados cinco passeios acompanhados com uma pessoa com baixa visão e quatro com cegueira nas cidades de Joinville/SC, Florianópolis/SC e São Paulo/SP. Todos os passeios tiveram seus trajetos envolvendo o uso do transporte coletivo precedido pelo a pé, sendo um deles por metrô e os demais por ônibus. O método foi desenvolvido por Dischinger e objetiva identificar a percepção do espaço pelo usuário, de forma que o pesquisador o acompanhe sem conduzi-lo ou ajudá-lo. As conversas são gravadas e pontos relevantes fotografados. (DISCHINGER, 2000)

${ }^{4}$ Disponível em http://www.vercompalavras.com.br/definicoes. Acessado em maio de 2016.

${ }^{5}$ Entrevista disponível em http://g1.globo.com/sc/santa-catarina/noticia/2016/04/descricao-permite-cegos-vivenciar-experiencia-de-irmirante-em-sc.html);

${ }^{6}$ Entrevista disponível em http://ndonline.com.br/joinville/noticias/301751-deficientes-visuais-conhecem-o-mirante-de-joinville.html;

${ }^{7}$ Os áudios podem ser escutados através do site: https://www.joinville.sc.gov.br/servicos/visitar-o-mirante-de-joinville/.

NOTA DO EDITOR (*) O conteúdo do artigo e as imagens nele publicadas são de responsabilidade do(s) autor(es). 